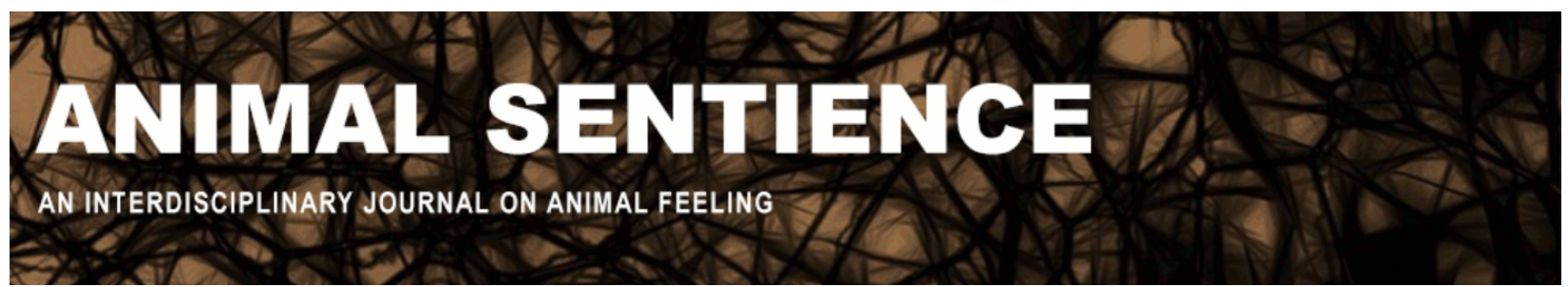

Abdai, Judit and Miklósi, Ádám (2018) Displaying jealous behavior versus experiencing jealousy. Animal Sentience 22(21)

DOI: $10.51291 / 2377-7478.1364$

Date of submission: 2018-08-09

Date of acceptance: 2018-08-14 (c) 


\title{
Displaying jealous behavior versus experiencing jealousy
}

Commentary on Cook et al. on Dog Jealousy

\author{
Judit Abdai \\ MTA-ELTE Comparative Ethology Research Group, Hungary \\ Ádám Miklósi \\ Department of Ethology \\ Eötvös Loránd University, Hungary \\ and \\ MTA-ELTE Comparative Ethology Research Group, Hungary
}

\begin{abstract}
Jealous behavior is the manifestation of complex behavioral interactions initiated by an individual who aims to maintain an important social relationship that is threatened by a rival. Researchers prefer to focus on the emotion thought to control this behavior, "jealousy," before understanding the mechanisms of the behavior. Researchers conducting recent behavioral studies on jealous behavior in dogs are still struggling to find strong experimental evidence. Thus, the positive correlation between amygdala activation and reported aggression in dogs described in Cook et al.'s target article is far from constituting evidence for "jealousy" in dogs.
\end{abstract}

Judit Abdai is a doctoral candidate working currently as an assistant research fellow at the MTA-ELTE Comparative Ethology Research Group in Hungary. Her main interest is in animal-robot interaction. Website

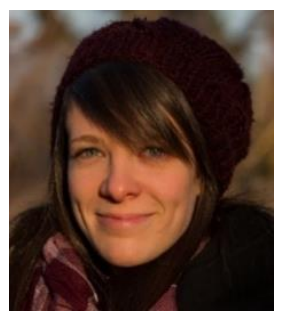

Ádám Miklósi, Professor and Head, Department of Ethology, Eötvös Loránd University, is leader of the Comparative Ethology Research Group funded by the Hungarian Academy of Sciences as well as cofounder and leader of the Family Dog Project, and author of the book Dog Behaviour, Evolution, and Cognition. Website

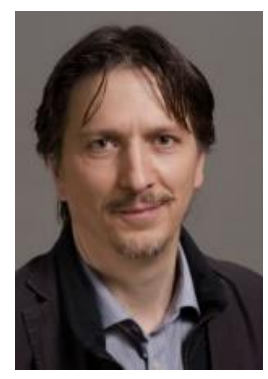

Jealous behavior emerges when an important social relationship of an individual is threatened by a third-party, a rival individual (e.g., Parrot and Smith 1993; Mize and Jones 2012; Hart 2016). Considering that social relationships (e.g., parent-offspring, sexual/romantic relationship) are crucial for fitness and survival in group-living species, behavior that facilitates maintaining these relationships is considered to be adaptively advantageous. Jealous behavior is probably widespread among nonhuman animals, but it has mainly been studied in humans and most data are from sexual/romantic relationships (e.g., Harris 2002, 2003; Takahashi et al. 2006). However, this social behavior also manifests in other social relations. For example, human infant studies 
suggest that jealous behavior emerges early during development when the mother focuses her attention on a potential social rival (e.g., Hart and Carrington 2002; Mize and Jones 2012).

1. Putting the cart before the horse. It is often the case that researchers prefer to demonstrate the "emotion" before understanding the function and the mechanism of the behavior under study. This seems to be the case in the study by Cook et al. (2018). Jealous behavior is based on complex behavioral interactions initiated by the subject and dependent on contextual factors. It is usually a manifestation of at least three tactics, each of which is represented by different types of behavior: (1) removal of the rival from the vicinity by ritualized or direct aggressive behavior; (2) attempts to stop social interaction by physically separating the rival from the social partner; (3) re-directing the attention of the partner onto the subject.

All this is well-reflected in the literature on emotions where jealousy is usually categorized as being a "secondary emotion" or "blended emotion" involving a set of "primary emotions" (see Hart and Legerstee 2013). Thus, in dogs, any measure of aggressiveness per se does not support the existence of jealousy but only the presence of "anger".

2. The importance of functional analogies. Whereas jealous behavior can have important adaptive value in mate choice, this scenario is probably not applicable to dogs. Much earlier research had indicated that dogs' attachment to their owners is functionally comparable to parent-filial attachment (e.g., Topál et al. 1998; for a review, see Prato-Previde and Valsecchi 2014). In line with this, a small set of recent experiments has aimed to demonstrate that jealous behavior may emerge in dogs when their relationship is threatened by a third-party individual (Harris and Prouvost 2014; Abdai et al. 2018; Prato-Previde et al. 2018a, b).

Independent of how successful these studies were in revealing jealous behavior in dogs (see below), three of them could not detect any agonistic behavior in the experimental situation. The lack of aggression can be explained by the socialization history of the family dogs that were tested, but also by the possibility of removing the rival without attacking. So we would argue that just as aggressive tendencies do not suggest the presence of jealous emotion in dogs, dogs may experience the activation of the emotion of "jealousy" in the absence of any anger. Note that this is similar to the case of human infants.

3. Choosing the right method. To date four behavioral studies have investigated the emergence of jealous behavior in dogs (Harris and Prouvost 2014; Abdai et al. 2018; Prato-Previde et al. 2018a, b). In the target article, Cook et al. used a modified procedure published by Harris and Prouvost (2014). Unfortunately, Harris et al.'s method is not sensitive enough to confirm that dogs discriminate between social and non-social test partners as potential intruders in their relationship. This would be an important factor in jealous behavior. In addition, Prato-Previde et al. (2018b) show that a dog's behavior when the owner attends to a fake dog does not fulfil the criteria of jealous behavior.

Two recent studies used real dogs as potential rivals. Abdai et al. (2018) were able to show that dogs discriminate between social and non-social participants when it comes to owneroriented behaviors; they try to sever the interaction between their owner and their rival. However, with a real dog as a potential rival, it is not always possible to find strong evidence for jealous behavior (see Prato-Previde et al. 2018a). 
Thus using a fake dog as a potential rival in Cook at al. has proved to be problematic in studying jealous behavior (see also Prato-Previde et al. 2018b and the commentary of PratoPrevide \& Valsecchi 2018). Moreover, bringing food (which was never used in the behavioral studies) into the social interaction could also have interfered with the rival context. The subject dogs may have been responding to the loss of food rather than a threat to their relationship with the owner, especially if they did not consider the fake dog a rival. Note also that competition for food could be interpreted as "envy" rather than "jealousy".

4. Are "single" neural measures enough to reveal a complex emotion? Cook et al.'s exclusive focus on the amygdala is also problematic. First, higher activation in the amygdala has also been linked to several other affective states (see e.g., Zald 2003; Harmon-Jones and Harmon-Jones 2018), some of which might be relevant here (see above). Second, as noted, jealous behavior is more complex than just heightened aggression. Attempts to divert the attention of the valued social partner or to separate them from the rival are both important components too. Prior fMRI research on jealousy in humans has found increased activity not only in the amygdala but in other brain regions as well (e.g., Takahashi et al. 2006; Harmon-Jones et al. 2009; Kelley et al. 2015). Thus measuring amygdala activation alone does not provide enough information (see also the commentary of Harmon-Jones 2018).

5. Cross-species analogies - need for caution. Does all this mean that dogs do not experience jealousy? No. Absence of evidence is not evidence of absence. Abdai et al. (2018) were able to show that dogs' behavior in a jealousy-evoking situation, using real dogs as potential rivals, fulfils the functional criteria of jealous behavior, excluding some other explanations (but see PratoPrevide et al. 2018a). Does this mean that dogs do experience "jealousy"? No. First, it would be important to include further control conditions (e.g., testing with a stranger instead of the owner or other potential rivals). Second, and more important, we are deliberately referring to our findings as jealous behavior (from a functional perspective), rather than jealousy for a reason. As indicated above, researchers prefer to focus on the emotional state underlying the behavior, but it should be emphasized that the emotion itself is obscure not only in nonhuman species, but in humans as well. The cultural agreement on jealousy in human species provides only a starting hypothesis for the case of dogs, rather than a "proof" of the existence of this emotional state. In humans, the existence of large individual differences raises the question of whether even we humans all experience jealousy in the same way.

6. Next steps. Knowledge about jealous behavior and its emotional representation ("jealousy") is still sparse. Numerous unanswered questions remain: Is jealousy triggered in different situations (e.g., parent-offspring vs. romantic relationship) driven by the same cognitive mechanism? Is jealous behavior in human children comparable to that in the human adult? What lies behind individual differences in displaying jealous behavior? Cook et al.'s results are interesting in showing a correlation between amygdala activation and reported aggression in dogs, but they fall short on supporting the presence of "jealousy". We should not yet refer to jealous behavior in nonhuman species as jealousy, or a "primordial" form of jealousy; but we also should not state that nonhuman species do not or cannot experience jealousy. Given the experimental support that exists to date, "jealous behavior" is a better description for the time being. 


\section{References}

Abdai, J., Baño Terencio, C., Pérez Fraga, P., \& Miklósi, Á. (2018). Investigating jealous behaviour in dogs. Scientific Reports, 8, 8911.

Cook, P., Prichard, A., Spivak, M., \& Berns, G. S. (2018). Jealousy in dogs? Evidence from brain imaging. Animal Sentience 22(1).

Harmon-Jones, E., \& Harmon-Jones, S. K. (2018). On jealousy, envy, sex differences and temperament in humans and dogs. Animal Sentience 22(8).

Harmon-Jones, E., Peterson, C. K., \& Harris, C. R. (2009). Jealousy: Novel methods and neural correlates. Emotion, 9, 113-117.

Harris, C. R. (2002). Sexual and romantic jealousy in heterosexual and homosexual adults. Psychological Science, 13, 7-12.

Harris, C. R. (2003). A review of sex differences in sexual jealousy, including self-report data, psychophysiological responses, interpersonal violence, and morbid jealousy. Personality and Social Psychology Review, 7, 102-128.

Harris, C. R., \& Prouvost, C. (2014). Jealousy in dogs. PLoS One, 9, e94597.

Hart, S. L. (2016). Proximal foundations of jealousy: Expectations of exclusivity in the infant's first year of life. Emotion Review, 8, 358-366.

Hart, S. L., \& Legerstee, M. (2013). Handbook of jealousy: Theory, research, and multidisciplinary approaches. West Sussex, UK: Wiley-Blackwell.

Hart, S., \& Carrington, H. (2002). Jealousy in 6-month-old infants. Infancy, 3, 395-402.

Kelley, N. J., Eastwick, P.W., Harmon-Jones, E., \& Schmeichel, B. J. (2015). Emotion jealousy increased by induced relative left frontal cortical activity jealousy increased by induced relative left frontal cortical activity. Emotion, 15, 550-555.

Mize, K. D., \& Jones, N. A. (2012). Infant physiological and behavioral responses to loss of maternal attention to a social-rival. International Journal of Psychophysiology, 83, 16-23.

Parrot, W. G., \& Smith, R. H. (1993). Distinguishing the experiences of envy and jealousy. Journal of Personality and Social Psychology, 64, 906-920.

Prato-Previde, E., \& Valsecchi, P. (2014). The immaterial cord: The dog-human attachment bond. In: Kaminski, J., \& Marshall-Pescini, S. (Eds.), The social dog (pp. 165-189). Boston: Academic Press.

Prato-Previde, E., \& Valsecchi, P. (2018). What is it like to be a jealous dog?. Animal Sentience 22(16).

Prato-Previde, E., Nicotra, V., Fusar Poli, S., Pelosi, A., \& Valsecchi, P. (2018a). Do dogs exhibit jealous behaviors when their owner attends to their companion dog? Animal Cognition, 21, 703-713.

Prato-Previde, E., Nicotra, V., Pelosi, A., \& Valsecchi, P. (2018b). Pet dogs' behavior when the owner and an unfamiliar person attend to a faux rival. PLoS One, 13, e0194577.

Takahashi, H., Matsuura, M., Yahata, N., Koeda, M., Suhara, T., \& Okubo, Y. (2006). Men and women show distinct brain activations during imagery of sexual and emotional infidelity. Neurolmage, 32, 1299-1307.

Topál, J., Miklósi, Á., \& Csányi, V. (1998). Attachment behaviour in the dogs (Canis familiaris): A new application of the Ainsworth's (1969) Strange Situation Test. Journal of Comparative Psychology, 112, 219-229.

Zald, D. H. (2003). The human amygdala and the emotional evaluation of sensory stimuli. Brain Research Reviews, 41, 88-123. 